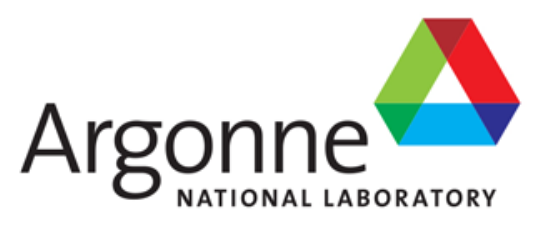

ANL-18/05

\title{
Advanced Materials and Technologies for Resilient Infrastructure Systems
}

Argonne National Laboratory 


\begin{abstract}
About Argonne National Laboratory
Argonne is a U.S. Department of Energy laboratory managed by UChicago Argonne, LLC under contract DE-AC02-06CH11357. The Laboratory's main facility is outside Chicago, at 9700 South Cass Avenue, Argonne, Illinois 60439. For information about Argonne and its pioneering science and technology programs, see www.anl.gov.
\end{abstract}

\title{
DOCUMENT AVAILABILITY
}

Online Access: U.S. Department of Energy (DOE) reports produced after 1991 and a growing number of pre-1991 documents are available free via DOE's SciTech Connect (http://www.osti.gov/scitech/).

Reports not in digital format may be purchased by the public from the National Technical Information Service (NTIS):

U.S. Department of Commerce

National Technical Information Service

5301 Shawnee Road

Alexandria, VA 22312

www.ntis.gov

Phone: (800) 553-NTIS (6847) or (703) 605-6000

Fax: (703) 605-6900

Email: orders@ntis.gov

Reports not in digital format are available to DOE and DOE contractors from:

U.S. Department of Energy

Office of Scientific and Technical Information

P.O. Box 62

Oak Ridge, TN 37831-0062

\footnotetext{
Disclaimer

This report was prepared as an account of work sponsored by an agency of the United States Government. Neither the United States Government nor any agency thereof, nor UChicago Argonne, LLC, nor any of their employees or officers, makes any warranty, express or implied, or assumes any legal liability or responsibility for the accuracy, completeness, or usefulness of any information, apparatus, product, or process disclosed, or represents that its use would not infringe privately owned rights. Reference herein to any specific commercial product, process, or service by trade name, trademark, manufacturer, or otherwise, does not necessarily constitute or imply its endorsement, recommendation, or favoring by the United States Government or any agency thereof. The views and opinions of document authors expressed herein do not necessarily state or reflect those of the United States Government or any agency thereof, Argonne National Laboratory, or UChicago Argonne, LLC.
} 


\section{Advanced Materials and Technologies for Resilient Infrastructure Systems}

by

H.C. Kim, M.C. Clifford, S.B. Darling, S.W. Snyder, M. Kaminski, C. Chen, A. Heifetz, A. Sumant, K. Hardy, M. Biruduganti, and C.M. Macal Argonne National Laboratory

March 2018 



\section{CONTENTS}

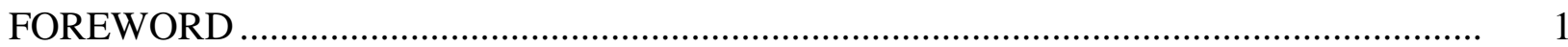

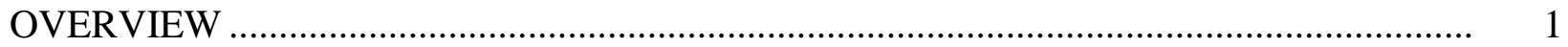

1 SECTOR-SPECIFIC CHALLENGES AND OPPORTUNITIES ................................. 3

1.1 Materials and Technologies for the Energy Sector .............................................. 3

1.2 Sensors and Treatment Systems for the Water and Wastewater Sector ................... 6

1.3 Structural Materials for Transportation and Nuclear Sectors .................................. 7

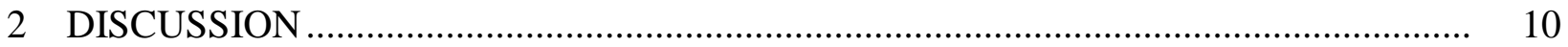

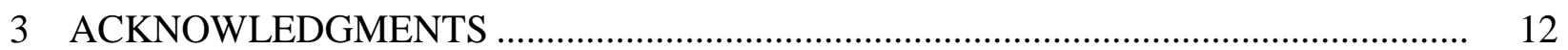

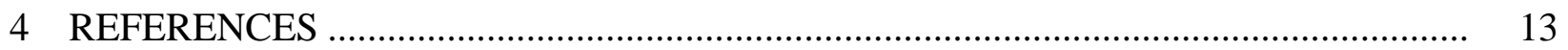

\section{FIGURES}

1 Extreme Weather Events Resulting in Damages in Excess of \$1 Billion. For 2017, the Number of Events Shown is as of October 6, 2017.

2 Left: Weather and Physical Attack Led to the Greatest Number of Electric Power Disruption Events between 2011 and 2014. Right: Major Outages Resulting in the Loss of Electric Service to More Than 50,000 Customers for 1 Hour or More.

\section{TABLE}

1 R\&D at Argonne for Resilient Infrastructure Materials, Components, and Systems 
This page intentionally left blank. 


\title{
ADVANCED MATERIALS AND TECHNOLOGIES FOR RESILIENT INFRASTRUCTURE SYSTEMS
}

\author{
H. Kim, M.C. Clifford, S.B. Darling, S.W. Snyder, M. Kaminski, C. Chen, A. V. Sumant, \\ A. Heifetz, K. Hardy, M. Biruduganti, and C.M. Macal
}

\section{FOREWORD}

This report is a survey of the capabilities at Argonne National Laboratory that can enable bridging the gap between discovery science and applications to enhance resilience across various critical infrastructures, including energy, transportation, water, and nuclear.

\section{OVERVIEW}

Infrastructure is largely unnoticed until it breaks down and services fail. This includes water supplies, gas pipelines, bridges and highways, phone lines and cell towers, and the electric grid - all of the complex systems that keep our societies and economies running. The secure and reliable functioning of our nation's critical infrastructure is required; however, U.S. infrastructures face a rising frequency and severity of natural disasters (Figure 1), and a growing number and sophistication of physical and cyber attacks. With increasing technological and economic progress, infrastructures are growing more interconnected, necessitating new considerations for their security. Recent disasters such as Superstorm Sandy provide profound insights into how non-linear interactions combine with network effects to trigger a cascade of events across interdependent systems. Compounding these risks is the degrading condition of infrastructure assets, which interacts in subtle ways with environmental stressors to magnify the impact of disasters (U.S. Department of Homeland Security [DHS] 2010). ${ }^{1}$

Meeting these challenges requires communities to strengthen existing infrastructure and build new systems based on modern designs, technologies, and methods that account for growing demand in an increasingly urbanized and connected world. While progress will depend on multiple policy and market drivers, scientific innovation will provide the necessary knowledge, technologies, and enabling materials. As a U.S. Department of Energy (DOE) national lab, Argonne National Laboratory is well positioned to leverage its world-class facilities and expertise in fields ranging from nano-scale materials to large-scale manufacturing to drive integrated research, development, and deployment (RD\&D) for resilient infrastructure systems.

1 In its quadrennial assessment, the American Society of Civil Engineers (ASCE) rated the current condition of our nation's infrastructures with an overall grade of D+. Grades were assigned according to eight criteria, including capacity, condition, public safety, and resilience. The ASCE estimates that $\$ 4.6$ trillion is needed by 2025 to bring U.S. infrastructure to acceptable standards (ASCE 2017). 


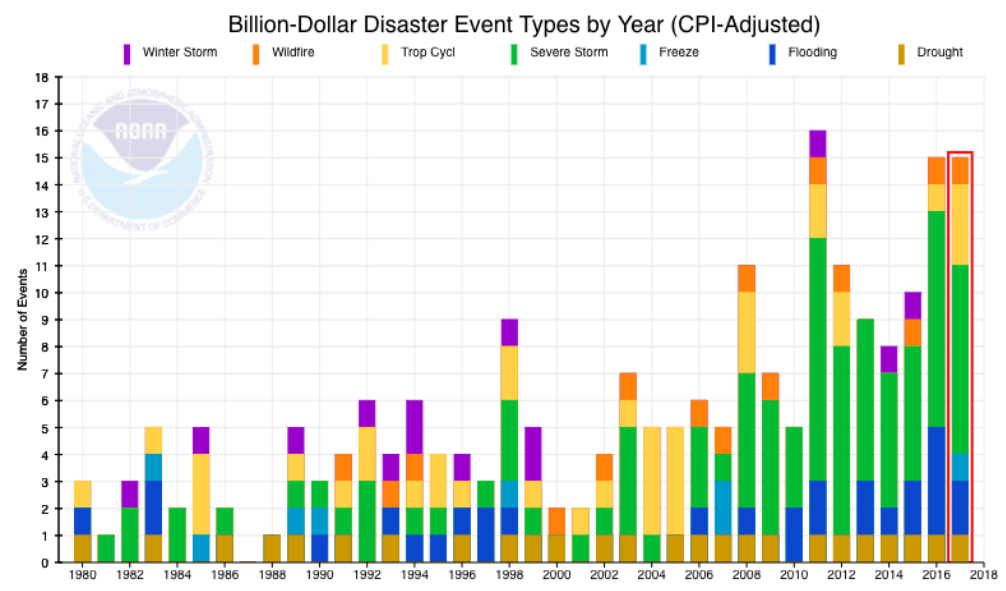

FIGURE 1 Extreme Weather Events Resulting in Damages in Excess of \$1 Billion. For 2017, the Number of Events Shown is as of October 6, 2017. (Source: National Oceanic and Atmospheric Administration 2018)

In 2015, Argonne established the Resilient Infrastructure Initiative (RII) to focus RD\&D to assess and address critical systems resilience (Clifford 2016). As a first priority, RII efforts are focusing on developing models and high-fidelity methodologies to capture interdependencies across the lifeline sectors. ${ }^{2}$ To date, the RII team has built integrated systems models to identify critical nodes and downstream dependencies for electric power and natural gas. While these models were developed primarily as tools for planners, operators, and responders, they can also be used to inform development in technologies and materials for resilience. Argonne researchers can integrate new component designs into systems-wide models to deliver insights on the value added of emerging technologies to systems-level properties, such as risk, vulnerabilities, and performance measures. Argonne envisions a joint, coordinated effort that integrates risk assessment models with technology development.

In the longer term, RII is integrating expertise across the laboratory to drive research in technologies and advanced materials to address critical infrastructure needs. This paper highlights some of the research and development $(R \& D)$ challenges for infrastructure sectors and the intersection with Argonne's capabilities in technologies and advanced materials.

2 Lifeline sectors include Energy, Water, Transportation, and Communications. 


\section{SECTOR-SPECIFIC CHALLENGES AND OPPORTUNITIES}

\subsection{MATERIALS AND TECHNOLOGIES FOR THE ENERGY SECTOR}

The Energy Sector is overseen by DOE at the federal level and consists of three interrelated segments: electric power generation and transmission, residential and industrial energy use, and transportation fuels. Primary energy sources for all segments include oil, natural gas, nuclear fuel, renewables, and coal. Mitigating energy disruptions is particularly important because other critical infrastructures rely on energy services to operate. Transmission, storage, and distribution (TS\&D) assets for electricity are most vulnerable to natural phenomena, with weather being the leading cause of disruptions since 2005 (Figure 2). DOE has placed a high imperative on protecting the electric power grid from weather and high-intensity, low-frequency (HILF) events, such as coordinated attacks and severe geomagnetic disturbances (DOE 2015). Today's electric power grid is evolving in technological and operational complexity toward an agile and modernized grid of the future, and utilities and agencies are expressing renewed interest in technologies, control systems, and critical infrastructure protection standards.

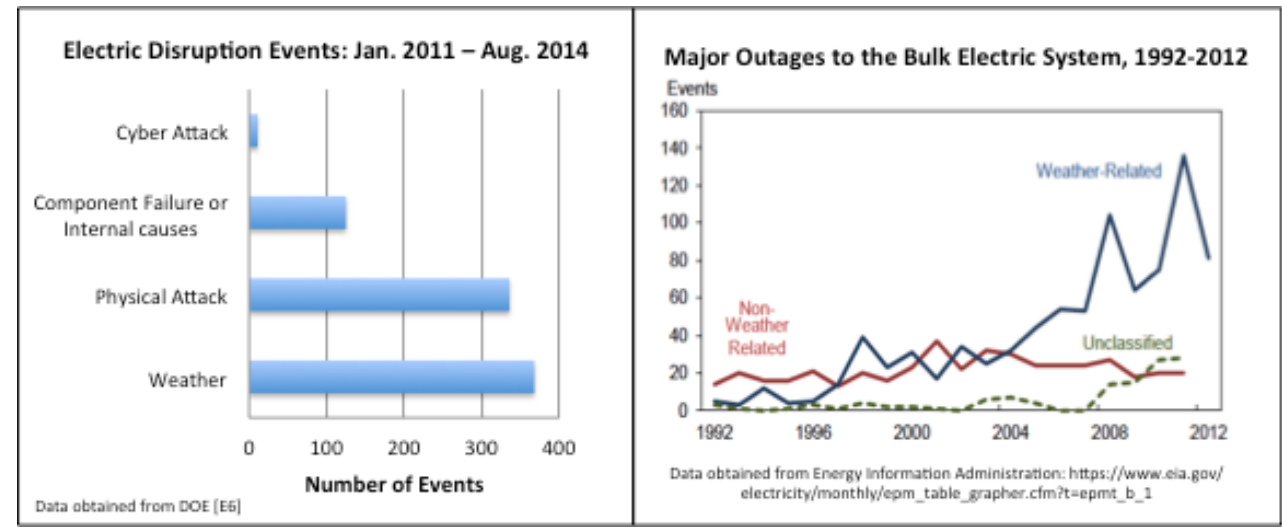

FIGURE 2 Left: Weather and Physical Attack Led to the Greatest Number of Electric Power Disruption Events between 2011 and 2014. Right: Major Outages Resulting in the Loss of Electric Service to More Than 50,000 Customers for 1 Hour or More. (The leading cause of major outages is weather, followed by equipment failure.)

Argonne leads a broad portfolio of distributed generation solutions for providing load relief in congested grid locations, maintaining emergency power to critical services and infrastructures, and improving visibility and agility for operators during an event (Wang et al 2014; Argonne National Laboratory undated). While emerging smart grid technologies have the potential for improving grid resilience, incorporating these devices for enhanced system restoration in response to severe events is a complex and challenging task. Integrated solutions are needed to aid utilities in developing comprehensive, agile, and adequate strategies for restoration. Because traditional restoration strategies face many challenges for outages under extreme weather events, system-level resilience requires multiple approaches to obtain solutions. 
These approaches include data analytics and distribution automation techniques to improve the situational awareness after disasters; advanced optimization techniques to improve the crew and resource allocation and dispatch; and advanced control methods to enable supply continuity utilizing distributed energy resources. To address these needs, Argonne is developing integrated decision support tools for distribution system restoration that will assist electric utilities in improving system restoration under extreme events. Multiple sources of information are integrated to enhance situational awareness regarding the damage after the event, and crew and resource dispatch can be conducted efficiently by using advanced optimization techniques (Chen et al. 2016).

Argonne's extensive work in grid technologies also includes the DOE Electric VehicleSmart Grid Interoperability Center (ANL-IOC), which focuses on developing technology and standards for vehicle-grid connectivity, communication, and interoperability. It also facilitates global harmonization of interoperability requirements and standards. The scope has expanded beyond vehicles to include integration with distributed energy resources and building systems, and applying Argonne-developed metering, communication, and integrated control technologies to other grid-connected devices and local grids. One of the main thrust areas for ANL-IOC is the development and verification of enabling technologies for grid connectivity and communication, including sub-meters, communication controllers, smart charge adapters, and diagnostic and compliance tools. Using the Argonne Smart Energy Plaza's microgrid, ANL-IOC focuses on testing metering, communication, and integrated control technologies in a flexible network of grid-connected devices. The center also develops open source solutions for grid integration, for example, by using protocol 'translators' and an Internet of Things approach to harmonize communication among vehicles, buildings, distributed energy resources, and storage.

At the system level, shifting from a centralized to a more distributed generation paradigm will improve grid resiliency by enhancing self-sufficiency, reliability, and redundancy of design. Argonne's Distributed Energy Research Center (DERC) offers many capabilities, such as additive manufacturing for distributed generation, combined heat and power (CHP) systems, and internal combustion engines. Some of the technologies pursued at DERC include novel ignition systems, air pretreatment with gas separation membranes, combustion diagnostics, and locally available opportunity fuels with low-energy content. Because fuel is deemed the largest operational cost for distributed generation, improving engine efficiency through these methods has great impact for market adoption. To that end, Argonne has developed and demonstrated various high-energy ignition systems to improve efficiency in stationary engines while simultaneously reducing nitrogen oxide $\left(\mathrm{NO}_{\mathrm{x}}\right)$ emissions using ultra-lean or dilute combustion (Biruduganti et al. 2010). DERC also houses other experimental facilities that enable research in micro-turbines and small-scale distributed generation, such as micro-CHP.

\section{Aging components at full capacity:}

$\$ 177$ billion investment needed by 2025 to bring electric infrastructure to acceptable standards

At the component level, one of the bottlenecks in improving electric power grid resilience lies at the power generation or receiving end, particularly with power electronics that handle high voltages and currents. Traditional grid electronics are often based on silicon materials, whose properties degrade dramatically at higher
640,000 miles of high-voltage transmission lines at full capacity

$70 \%$ of Large Power Transformers are over 25 years beyond their designed lifespan 
operating temperatures. Other components, such as transformers, have design features that make them highly susceptible and difficult to recover from disasters (Electric Power Research Institute 2014). Indeed, the primary risk scenarios for the power grid involve events that disable transformers in multiple generating stations, leading to prolonged outages over wide geographic areas (DOE 2012, 2015).

Next-generation solid-state devices based on wide bandgap (WBG) materials will play a crucial role in enhancing electric power grid capabilities, protecting critical assets, and enabling breakthroughs for resilient transformer design (Energetics Incorporated 2015). While WBG materials such as $\mathrm{SiC}$ and $\mathrm{GaN}$ have been actively researched for these applications, wider bandgap materials like diamond are gaining great interest because of their outstanding electrical, thermal, and mechanical properties. Argonne is developing diamond materials for solid-state electronics wherever high frequencies, powers, temperatures, or voltages are required. Recent work at Argonne has demonstrated the feasibility of integrating diamond with other WBG materials such as GaN for efficient heat management. The ability to directly integrate diamond with GaN through low-temperature diamond deposition processes developed at Argonne (Goyal et al. 2012) represents a game-changing step for solid-state devices, with high impact potential for the power industry.

At the materials level, the resilience of infrastructure components is often limited to material properties in extreme environments. New developments such as coatings and hybrid materials offer a pathway toward meeting goals for increased capacity and reliability of components. Argonne has decades of experience in testing and reliability analysis for industry to understand component failure under conditions of overload and corrosion and has engineered products for industry, including carbon films and heat transfer fluids to minimize loss.

Argonne is harnessing the unique properties of materials at the nanoscale to control and tailor desired properties. One example is the field of covetics, an emerging science based on nano-carbon infusion into a range of metals. Covetic nanomaterials exhibit significantly enhanced properties over traditional metals and are currently being explored with industry partners for high-voltage transmission lines and capacity load relief (Forrest 2016). Other advanced materials can provide failure mitigation under extreme thermal, chemical, and tribological stresses (Singh et al. 2016). Examples include graphene-based superlubricity (Berman et al. 2015), first achieved at Argonne, which can increase the reliability of power generation turbines, wind turbines, and magnetic disc storage devices, and is currently being developed with automotive industry partners.

TS\&D infrastructures for natural gas are generally less vulnerable than electric power, but their recovery is complicated by the need to locate and repair underground breakages. Highrisk components include transmission pipelines, compressor stations, and distribution systems, whose disruption could result in significant outages. Among concerns for natural gas are pipeline breakage, which occurs from natural disasters, material failure from corrosion and temperature, and breakages propagating from collocated pipelines (DOE 2015). Another concern for natural gas comes from methane emissions (DOE 2015), most of which arise from underlying leakprone materials. Argonne has developed highly sensitive methane chemoresistive sensors through the use of atomic layer deposition to functionalize multiwalled carbon nanotubes 
(Humayun et al. 2015). As a partner of DOE's ExtremeMat research consortium, Argonne is designing materials for resilience under a wide range of extreme conditions, including for the natural gas sector. This integrated effort across modeling, validation, and manufacturing will greatly enhance Argonne’s impact potential for energy and other sectors.

\subsection{SENSORS AND TREATMENT SYSTEMS FOR THE WATER AND WASTEWATER SECTOR}

In the Water and Wastewater (W\&W) Sector, the U.S. Environmental Protection Agency (EPA) oversees the protection of drinking water and wastewater systems, ${ }^{3}$ whose disruption can cause severe public health and economic consequences. This sector consists of multiple components, including water sources, storage, treatment, and discharge; as well as monitoring systems and physical distribution networks. A significant risk in the W\&W Sector comes from natural disasters that impact water quality, quantity, and utilities' ability to function (DHS and EPA 2015). Other concerns include disruptive cyber events and manmade disasters that introduce chemical, biological, radiological, and nuclear (CBRN) contamination. In its 20162019 Strategic Action Plan, the EPA Office of Homeland Security identified three main R\&D objectives for water systems resilience: (1) detection and response to contamination events and disruptions, (2) systems assessment of vulnerabilities, and (3) understanding of the implications of design decisions on system resilience (EPA 2015). Water and wastewater are typically regulated, permitted, and managed at the state level, creating additional challenges to infrastructure resilience (e.g., see Mihelcic et al. 2017).

The development of sensitive detection and mitigation technologies is enabled by the ability to control and tailor material properties. Argonne's existing capabilities are well aligned to meet these needs (Kline-Schoder et al. 2015; Lee et al. 2015). An illustrative example is the development of functionalized magnetic structures that detect CBRN threats. Argonne pioneered the use of magnetic micro-particles for trace separations of radionuclides and developed key aspects of magnetic micro- and nanoparticle synthesis for biological threat agent isolation and detection. Such multifunctional magnetic structures are being integrated with sensor platforms and waterborne transport modeling tools. This integrated system combines various modulessample acquisition, sample processing, trace separations, sample analyses, and command/control and data access - and the entire system is contained within a submersible vehicle with current designs for a long-range autonomous underwater vehicle. This capability enables an integrated approach to CBRN scenarios through automated target detection, consequence assessment, and forensic analysis via fate/source tracing of contaminants.

Beyond municipal water, agricultural groundwater and industrial water are intricately intertwined with freshwater quality, food security, and energy production. With nearly one-fifth of the world's population living in areas of water scarcity, there is a global need for research to identify decontamination and purification processes that minimize cost and energy use compared

3 As defined by DHS, which oversees each sector along with sector-specific agencies. Beyond the W\&W Sector, numerous bodies govern water quality, pollution prevention, and offshore incidents. These include the Bureau of Safety and Environmental Enforcement and the U.S. Coast Guard. 
to currently available methods. Argonne is highly active in developing designer materials for water purification and pollution remediation, including functionalization of membrane interfaces and catalytic coatings for toxin degradation (Lee et al. 2016; Jaeger et al. 2014). For example, one of the most significant barriers to membrane separation technology for wastewater treatment is fouling of membrane surfaces. Argonne has developed a self-cleaning photocatalytic nanofiltration membrane by leveraging a biomimetic mineralization process to address the fouling challenge (Lv et al. 2017).

Advances in designer materials have the potential not only to improve performance of existing systems, but also to facilitate the development of new classes of technologies. One example is a new class of adsorbent material developed by Argonne for removal of contaminants at larger scales. A recent breakthrough in the technique of sequential infiltration synthesis has enabled an innovation, called Oleo sponge, designed to clean up oil spills even from the middle of the water column (Barry et al. 2017). These materials are coordinated to a substrate in a format that enables adsorbency from the environment and then separation of the contamination in a roll press. This approach has great potential for adaptation to other contaminants that are present in large volumes, including pathogens, radionuclides, and heavy metals. The technology, developed in partnership with the U.S. Coast Guard, could find broad application in response to natural and manmade disasters.

Desalination and related technologies are also of central importance in addressing water scarcity and other issues at the water-energy nexus. Argonne is driving integrated water-energy solutions that can treat water that is fit-for-purpose, thereby reducing energy demand and cost. A recent innovation is in materials and processes for electrokinetic purification of water. These platforms include resin wafer electrodeionization (RW-EDI) and capacitive deionization (CDI) (Pan et al. 2017). Unlike existing processes that remove the water from the brine, electrokinetic methods remove the salt and other charged species from the water. They are designed for a broad range of applications beyond seawater, such as brackish groundwater or reclaimed industrial wastewater. By providing alternative sources for water away from the sea coasts, Argonne is increasing the resilience of the overall water system. As desalination requires energy input, diluting salt into water can generate energy. Argonne is exploring storing the salt concentrate and running electrokinetic systems in reverse to provide power to the electric power grid at times of peak demand. This process will enable the water treatment plants to contribute to the reliability of the grid.

\subsection{STRUCTURAL MATERIALS FOR TRANSPORTATION AND NUCLEAR SECTORS}

The Transportation Sector, overseen by the U.S. Department of Transportation (DOT), consists of seven subsectors: aviation, maritime, highway, mass transit, freight rail, pipeline, and postal. Based on the experience and overall research themes at Argonne, the greatest potential for impact lies in the highway subsector, comprised of bridges, tunnels, and roadways. State and local governments own 97 percent of the highway infrastructure and share joint responsibilities with federal governments to monitor their needs (American Road and Transportation Builders Association 2018). Risks in this subsector include physical attacks, which can cause significant 
disruptions and long-term economic impairment. Extreme weather events and natural disasters have exacerbated vulnerabilities and are projected to have increased impacts through rising sea levels, storm surges, service disruptions, and materials degradation (U.S. Global Change Research Program 2014; DHS and DOT 2015). Damage at obvious chokepoints like bridges can delay emergency services and the recovery of other sectors during a widespread event. As officials consider the future of transportation networks, adaptations in design, operational changes, and new technologies and materials must be considered.

The U.S. Army Corps of Engineers (USACE) has identified continuous structural monitoring as a top R\&D priority for transportation-as well as other sectors such as dams and nuclear reactors (Weiss 2016; Cary 2016). With many highway assets aging, the role of selfsensing, self-healing, and self-correcting materials will be crucial in future resilient designs. While aging alone does not pose a safety hazard, the likelihood of failure from time-dependent effects and high-impact disasters increases substantially with age (DHS 2015). The ability to control material properties at the micro- and nanoscales will open up opportunities for smarter structures with self-diagnosing, self-repairing properties. Argonne can impact the Transportation Sector by extending its expertise in nanoscale materials to infrastructure applications. An example is a manufacturing method developed in collaboration with Argonne for nanowire production in kilogram quantities (Seley et al. 2011). These nanowires can be mixed into a concrete matrix and incorporated into building materials, allowing the detection of structural faults as they cut through the wires using impedance spectroscopy.

From a materials standpoint, infrastructure needs in the transportation and nuclear sectors include the development of advanced metallic, ceramic, and cementitious systems (Weiss 2016). Argonne developed a novel chemically bonded phosphate ceramic, known by its trade name Ceramicrete, that is well-suited for applications requiring high compressive strength and durability through temperature cycling (Sagoff 2008). The material gains its full strength in 24 hours, enabling rapid rebuilding following a disaster and extending its potential impact across other areas, including energy and military applications. Ceramicrete has been scaled up and demonstrated for use in bridges, highways, and the safe decommissioning of nuclear reactors.

In addition, advanced characterization techniques are needed to detect degradation in traditional construction materials such as metal and concrete. This is particularly important for high-value critical infrastructure such as major bridges and nuclear power plants (NPPs), where replacement of concrete structures is difficult and extremely costly. Other examples include space communications radar support installations, where

Aging design and failing materials

$\$ 145$ billion investment needed each year for 20 years to meet safety and economic goals for highways and bridges

63,000 bridges are structurally deficient

$20 \%$ of highway mileage failed to meet criteria for acceptable pavement degradation of supporting concrete can cause radar misalignment and disruptions to the mission. One of the most common deterioration mechanisms of aging concrete is alkali-silica reaction (ASR), the net result of which is to weaken structural resilience to extreme events such as earthquakes. Recent notable examples include structural damage in the Seabrook NPP in New Hampshire, and the 6th Street Viaduct Bridge in Los Angeles, which was demolished in 2016 due to safety concerns. Presently, methods exist for slowing down 
ASR, but there is no remediation for the process in existing structures, and diagnosed structures need continuous monitoring for damage progression. This task is complicated by the lack of methods for in-situ nondestructive characterization. The current industry approach to ASR evaluation consists of extraction of multiple cores within a structure for destructive laboratory testing.

To address the technology gap, Argonne is collaborating with a research industry partner to develop methods for in-situ nondestructive evaluation (NDE) of ASR in concrete materials based on electrochemical impedance spectroscopy and microwave dielectric spectroscopy (Heifetz et al 2017). Combined with existing high-resolution imaging techniques, these methods could be used to nondestructively quantify the extent of structural deterioration and identify areas of greatest vulnerability where the most damage has occurred. Argonne's years of experience in NDE and deep expertise in analytical and numerical modeling and advanced signal processing are being used extensively for detection of failure in critical structures in transportation, power generation, and military sectors (Bakhtiari et al. 2018).

Finally, international user facilities at Argonne, such as the Advanced Photon Source (APS), have played a critical role in evaluation and development of structural materials. A recent highlight is a DOT Exploratory Advanced Research project aimed at developing next-generation transportation systems, in which Argonne scientists are using the APS for structural imaging of geopolymer cements and cement hydration with three-dimensional tomography (Hu et al. 2016). Understanding the physical and chemical properties that govern material performance will enable new robust designs, as well as micro- and macroscale predictions of behavior under a wide range of conditions. 


\section{DISCUSSION}

Across infrastructure sectors, utilities and government entities are seeking effective, lowcost solutions to increase the resilience of infrastructure systems. Argonne possesses the capabilities and expertise required at the cutting edge of materials discovery, synthesis, testing, and characterization. New computational capabilities at Argonne are enabling predictive modeling and in-silico design of advanced materials through techniques such as machine learning and high-throughput methods (Cherukara et al. 2016). Likewise, atomistic modeling is facilitating the characterization and understanding of failure at the atomic or molecular level in functional materials and devices (Rowland et al. 2014). In the future, computational capabilities will need to be extended across length scales from the atomic to the meso- and macroscopic regimes. Advances in multiscale modeling will thus be necessary to understand material performance in macroscopic systems and inform the design of complex infrastructure networks. Equally critical are innovations in manufacturing processes and scale-up of advanced materials, which present novel challenges and barriers to deployment. With an in-house facility for process R\&D and scale-up, Argonne develops scalable manufacturing processes and evaluates emerging manufacturing technologies to support materials deployment from concept validation through advanced development and production.

Argonne's extensive expertise resides in many divisions across the laboratory (see Table 1), from materials and computational science to nuclear engineering and energy systems. Argonne offers a unique ability to integrate these diverse contributions through internal programs, external partnerships, and scale-up and commercialization support. By marshaling the resources, expertise, and creativity both inside and outside the laboratory, researchers will envision unforeseen solutions and guide new architectures enabled by advanced technologies. In doing so, science and engineering will enable the resilient design of infrastructure systems to address future threats and risks posed to our nation. 


\section{TABLE 1 R\&D at Argonne for Resilient Infrastructure Materials, Components, and Systems}

\begin{tabular}{|c|c|}
\hline Sector/Subsector & Description \\
\hline $\begin{array}{l}\text { Water and } \\
\text { Wastewater }\end{array}$ & $\begin{array}{l}\text { Advanced membranes, coatings, and designer materials for purification and decontamination } \\
\text { Desalination and industrial water treatment } \\
\text { Water Research Initiative: separations and catalysis } \\
\text { Functionalized magnetic particles for selective separations of chemical and biological targets } \\
\text { Wide-area urban decontamination and implications for wastewater systems } \\
\text { Optical sensing of waterborne E.coli combining biological and nanosynthesis methods } \\
\text { Sensors and detectors for water quality }\end{array}$ \\
\hline $\begin{array}{l}\text { Structural } \\
\text { Materials for } \\
\text { Transportation } \\
\text { and Nuclear }\end{array}$ & $\begin{array}{l}\text { NDE of alkali aggregate reactions in concrete } \\
\text { Performance of structural materials (metals, ceramics, composites) in harsh corrosive environments } \\
\text { Reliability analysis for structural materials such as composites } \\
\text { Ceramic-based structural materials for high compressive strength, quick-setting, corrosion resistant, and } \\
\text { temperature cycling applications } \\
\text { Testing and failure analysis of components under conditions of overload and corrosion } \\
\text { Low-cost nanowire manufacturing with potential application for self-sensing structural materials }\end{array}$ \\
\hline $\begin{array}{l}\text { Electric Power } \\
\text { and Natural Gas }\end{array}$ & $\begin{array}{l}\text { Electric power transmission and distribution for grid resilience and restoration under extreme events } \\
\text { Stationary natural gas engines-improving efficiency and cost through giant microphotonics (laser ignition) } \\
\text { Electric vehicle-smart grid interoperability } \\
\text { Covetic nanomaterials for enhanced electrical and thermal conductors } \\
\text { Tribology_testing and failure mitigation technologies for wind power industry } \\
\text { Heat transfer-nanofluids and covetics for cooling of power electronics } \\
\text { Thermal energy storage for concentrated solar power for up to } 12 \text { hours of backup power } \\
\text { Advanced coatings and lubricants } \\
\text { Wider penetration of fuel cells for resilient power generation, developing nonplatinum group metal catalysts } \\
\text { Thermal management and diamond-based solid state electronics } \\
\text { Solid-state superlubricity } \\
\text { Chemoresistive methane sensors for natural gas sector }\end{array}$ \\
\hline Crosscutting & $\begin{array}{l}\text { DOE Energy Materials Network: ExtremeMat Consortium } \\
\text { Manufacturing process R\&D, quality control, scale-up of new materials to kilogram quantities } \\
\text { Atomistic modeling to understand degradation processes and failure at the atomistic level } \\
\text { Predictive modeling to accelerate materials discovery and design } \\
\text { Testing and evaluation of materials for industry } \\
\text { Modeling of interdependent infrastructure systems }\end{array}$ \\
\hline
\end{tabular}




\section{ACKNOWLEDGMENTS}

We acknowledge many useful discussions with D. Singh, G. Krumdick, T. Krause, T. Rajh, G. Fenske, S. Gupta, U. Balachandran, J. Grudzinski, A. Roelofs, A. Greco, M. Magnuson, C. Weiss, A. Al-Ostaz, and D. Forrest.

The work presented in this paper was supported by the U.S. Department of Energy, Office of Science under contract number DE-AC02-06CH11357. If you would like more information regarding the Resilient Infrastructure Initiative presented in this paper, please contact Hyekyung (Clarisse) Kim at clarisse@anl.gov. 


\section{REFERENCES}

American Road and Transportation Builders Association, 2018, "Highways Policy: Scope of the U.S. Highway Network,” http://www.artba.org/government-affairs/policy-statements/highwayspolicy/.

American Society of Civil Engineers, 2017, “2017 Infrastructure Report Card,” http://www. infrastructurereportcard.org/cat-item/energy/.

Argonne National Laboratory, undated, "EV-Smart Grid Interoperability Center," https://www.anl.gov/energy-systems/project/ev-smart-grid-interoperability-center. See also Argonne's "Hydrogen and Fuel Cell Materials," https://www.anl.gov/cse/group/hydrogen-andfuel-cell-materials; "Distributed Energy Research Center," https://www.anl.gov/ energy-systems/facilities/distributed-energy-research-center; and "Energy Storage for Grid Integration of Renewable Energy," https://www.anl.gov/energy-systems/project/energy-storagegrid-integration-renewable-energy.

Bakhtiari, S., H. Chien, A. Heifetz, and T. Elmer, "Nondestructive Testing Research and Development Efforts at Argonne National Laboratory: An Overview," Materials Evaluation, The American Society for Nondestructive Testing (submitted).

Barry, E., A. Mane, J. Libera, J. Elam, and S. Darling, 2017, “Advanced Oil Sorbents Using Sequential Infiltration Synthesis,” J. Mater. Chem. A, 5:2929.

Berman, D., S. Deshmukh, S. Sankaranarayanan, A. Erdimir, and A. Sumant, 2015, "Macroscale Superlubricity Enabled by Graphene Nanoscroll Formation,” Science 348: 6239, 1118-1122.

Biruduganti, M., S. Gupta, B. Bihari, S. McConnell, and R. Sekar, 2010, “Air Separation Membranes - An Alternative to EGR in Large Bore Natural Gas Engines," J. Eng. Gas Turbines Power, 132:8, 082804, American Society of Mechanical Engineers (May).

Cary, S.V.. 2016, "USACE Research and Support Centers," slide presentation given at the Society of American Military Engineers FY2017 Department of Defense and Federal Agency Program Briefings, Alexandria, Virginia (March), http://www.ncmbc.us/docs/

SAME/2016/1100-1200_Centers_Final.pdf.

Chen, C., J. Wang, F. Qiu, and D. Zhao, 2016, "Resilient Distribution System by Microgrids Formation after Natural Disasters," IEEE Transactions on Smart Grid, 7:2 (March). See also, Lei, S., J. Wang, C. Chen, and Y. Hou, 2016, "Mobile Emergency Generator Pre-positioning and Real-time Allocation for Resilient Response to Natural Disasters," IEEE Transactions on Smart Grid, PP:99 (September); and Chen, C., J. Wang, and D. Ton, 2017, "Modernizing Distribution System Restoration to Achieve Grid Resiliency against Extreme Weather Events: An Integrated Solution,” Proceedings of the IEEE, 105:7 (May). 
Cherukara, M.J. B. Narayanan, A. Kinaci, K. Sasikumar, S. Gray, M. Chan, and S. Sankaranarayanan, 2016, "Ab Initio-based Bond Order Potential to Investigate Low Thermal Conductivity of Stanene Nanostructures,” The Journal of Physical Chemistry Letters, 7:19, http://pubs.acs.org/doi/abs/10.1021/acs.jpclett.6b01562.

Clifford, M., 2016, “The Resilient Infrastructure Initiative: Argonne National Laboratory,” Natural Hazards Center Vol. XL, No. 7 (November 2), https://hazards.colorado.edu/article/ the-resilient-infrastructure-initiative-argonne-national-laboratory.

DHS (U.S. Department of Homeland Security), 2015, “Aging and Failing Infrastructure Systems: Highway Bridges,” National Protection and Programs Directorate (September), http://cip.gmu.edu/wp-content/uploads/2015/09/OCIA-Aging-and-Failing-InfrastructureSystems-Highway-Bridges.pdf.

DHS, 2010, Aging Infrastructure: Issues, Research, and Technology, BIPS-01, Buildings and Infrastructure Protection Series (December), Office of Science and Technology, https://www.dhs.gov/xlibrary/assets/st-aging-infrastructure-issues-research-technology.pdf.

DHS and DOT (U.S. Department of Transportation), 2015, National Infrastructure Protection Plan: Transportation Systems Sector-specific Plan, https://www.dhs.gov/transportationsystems-sector.

DHS and EPA (U.S. Environmental Protection Agency), 2015, National Infrastructure Protection Plan: Water and Wastewater Systems Sector-Specific Plan, https://www.dhs.gov/ water-and-wastewater-systems-sector.

DOE (U.S. Department of Energy), 2015, Quadrennial Energy Review: Transforming U.S. Energy Infrastructures in a Time of Rapid Change, Chapter 2, "Increasing the Resilience, Reliability, Safety, and Asset Security of TS\&D Infrastructure,” Office of Policy, https://www.energy.gov/epsa/downloads/quadrennial-energy-review-first-installment.

DOE, 2012, “Large Power Transformers and the U.S. Electric Grid,” Infrastructure Security and Energy Restoration, Office of Electricity Delivery and Reliability (June), https://energy.gov/ sites/prod/files/Large\%20Power\%20Transformer\%20Study\%20-\%20June\%202012_0.pdf.

Electric Power Research Institute, 2014, “Considerations for a Power Transformer Emergency Spare Strategy for the Electric Utility Industry,” prepared for the U.S. Department of Homeland Security, Science and Technology Directorate (September), https://www.dhs.gov/sites/default/ files/publications/RecX\%20\%20Emergency\%20Spare\%20Transformer\%20Strategy-508.pdf.

Energetics Incorporated, 2015, Controlling the Flow: Next-Generation Power Electronics Systems for Tomorrow's Electric Grid, prepared in collaboration with K. Cheung (December), https://energy.gov/sites/prod/files/2016/06/f32/GIGA\%20Project\%20Summary.pdf. See also U.S. Department of Energy, 2016, Power Electronics Systems for the Electric Grid: Ensuring the Flexibility, Reliability, and Resilience of the Future Grid, Office of Electricity Delivery and 
Energy Reliability, https://energy.gov/sites/prod/files/2016/06/f32/

OE\%20Factsheet\%20Power\%20Electronics_0.pdf.

EPA, 2015, Homeland Security Strategic Research Action Plan: 2016-2019, EPA 601/K-15/001, Office of Research and Development Homeland Security (November), https://www.epa.gov/ research/homeland-security-strategic-research-action-plan-2016-2019.

Forrest, S., 2016, “AMO Program in Covetic Nanomaterials,” DOE Advanced Manufacturing Office Peer Review, Washington, D.C. (June), https:/energy.gov/sites/prod/files/2016/ 07/f33/R1z -AMO Program in Covetic Nanomaterials_Forrest_introcovetic panel 2016_compliant.pdf.

Goyal, V., A.V. Sumant, D. Teweldebrhan, and A.A. Balandin, 2012, "Direct Low-temperature Integration of Nanocrystalline Diamond with GaN Substrates for Improved Thermal Management of High-Power Electronics,” Advanced Functional Materials, 22:7, 1525-1530.

Heifetz, A., S. Bakhtiari, J. Lu, I. Aranson, V. Vinokur, and F. Bentivegna, 2017, "Development of Microwave and Impedance Spectroscopy Methods for In-situ Nondestructive Evaluation of Alkali Silica Reaction in Concrete,” American Institute of Physics Conference Proceedings, 1806:120003, http://aip.scitation.org/doi/abs/10.1063/1.4974708.

Hu, Q., et al., 2016, "Direct Three-dimensional Observation of the Microstructure and Chemistry of $\mathrm{C}_{3} \mathrm{~S}$ Hydration,” Cement and Concrete Research, 88:157 (October), https://www.sciencedirect.com/science/article/pii/S0008884615300120.

Humayun, M., et al., 2015, “ZnO Functionalization of Multi-walled Carbon Nanotubes for Methane Sensing at Single PPM Concentration Levels,” Journal of Vacuum Science \& Technology B, 33:6, 1-7, American Institute of Physics, New York, New York, https://cfpub.epa.gov/si/si_public_record_report.cfm?dirEntryId=310043.

Jaeger, H., J. He, and X. Lin, 2014, "Nanoparticle-based Desalination and Filtration System,” U.S. Patent 20140246384 (September 4).

Kline-Schoder, R., P. Sorensen, M. Kaminski, C. Scholin, J. Birch, and M. Walsh, 2015, “Automated Water-Borne Chemical/Biological Threat Detection,” presented at 2015 CBD S\&T Conference, St. Louis, Missouri. See also Kaminski, M., N. Kivenas, C. Oster, W. Jolin, M. Magnuson, and K. Hepler, 2017, "Integrated Wash-Aid, Treatment, and Emergency Reuse System (IWATERS) for Strontium Contaminations," Proc. of the Waste Management Conference, Phoenix, Arizona, Paper 17390; and Kaminski, M., C. Mertz, N. Kivenas, and R. Demmer, 2016, Technical Improvements to an Absorbing Supergel for Radiological Decontamination in Tropical Environments," ANL/NE-16/9, Argonne National Laboratory, Nuclear Engineering Division.

Lee, A., J. Elam, and S. Darling, 2016, "Membrane Materials for Water Purification: Design, Development, and Application,” Enviro. Sci.: Water Res. Technol., 2:17. See also Lee, A., et al., 
2017, “Conformal Nitrogen-doped $\mathrm{TiO}_{2}$ Photocatalytic Coatings for Sunlight-activated Membranes,” Adv. Sustainable Syst., 1:1600041, doi: 10.1002/adsu.20160041.

Lee, J., et al., 2015, “Fast, Ratiometric FRET from Quantum Dot Conjugated Stabilized Single Chain Variable Fragments for Quantitative Botulinum Neurotoxin Sensing,” Nanolett, 15:7161.

Lv, Y., et al., 2017, "Photocatalytic Nanofiltration Membranes with Self-cleaning Property for Wastewater Treatment,” Adv. Funct. Mater., 27:27, 1700251.

Mihelcic, J., et al., 2017, “Accelerating Innovation That Enhances Resource Recovery in the Wastewater Sector: Advancing a National Testbed Network,” Environmental Science and Technology, 51:14, http://pubs.acs.org/doi/abs/10.1021/acs.est.6b05917.

National Oceanic and Atmospheric Administration, 2018, "Billion-Dollar Weather and Climate Disasters: Time Series,” National Centers for Environmental Information (April 6), https://www.ncdc.noaa.gov/billions/time-series.

Pan, S., S. Snyder, H. Ma, Y. Lin, and P. Chiang, 2017, “Development of a Resin Wafer Electrodeionization Process for Impaired Water Desalination with High Energy Efficiency and Productivity,” ACS Sustainable Chem. Eng., 5:4, 2942-2948.

Rowland, C., W. Liu, D. Hannah, M. Chan, D. Talapin, and R. Schaller, 2014, “Thermal Stability of Colloidal InP Nanocrystals: Small Inorganic Ligands Boost High-temperature Photoluminescence,” ACS Nano, 8, 1:977, http://pubs.acs.org/doi/abs/10.1021/nn405811p. See also Trahey, L., et al., 2013, "Synthesis, Characterization, and Structural Modeling of Highcapacity, Dual Functioning $\mathrm{MnO}_{2}$ Electrode/Electrocatalysts for $\mathrm{LiO}_{2}$ Cells,” Advanced Energy Mater., 3:1, http://onlinelibrary.wiley.com/doi/10.1002/aenm.201200037/abstract.

Sagoff, J., 2008, “Innovative Cement Helps DOE Safeguard Nuclear Facilities,” Argonne National Laboratory (April), https://www.anl.gov/articles/innovative-cement-helps-doesafeguard-nuclear-facilities.

Seley, D.B., et al., 2011, "Electroplate and Lift Lithography for Patterned Micro/Manowires Using Ultrananocrystalline Diamond as a Resusable Template,” ACS Appl. Mater. Interfac., 3:4, 925-930, http://pubs.acs.org/doi/abs/10.1021/am101226w.

Singh, D., et al., 2016, “Heat Transfer Fluids Containing Nanoparticles,” U.S. Patent 9340720 (May 17). See also Greco, A., S. Sheng, J. Keller, and A. Erdemir, 2013, "Material Wear and Fatigue in Wind Turbine Systems,” Wear, doi: 10.1016/j.wear.2013.01.060, Elsevier VP, https:/tic.epfl.ch/files/content/sites/tic/files/courstribo/articles_courstribo/articles_2013/A7.pdf; and Erdimir, A., G. Fenske, O. Erylimaz, and R. Lee, 2003, "Method to Produce Ultra-low Friction Carbon Films,” U.S. Patent 20020041930 (April 15).

U.S. Global Change Research Program, 2014, "Highlights from Third National Climate Assessment,” http://nca2014.globalchange.gov/highlights. 
Wang, Z., B. Chen, J. Wang, J. Kim, and M. Begovic, 2014, "Robust Optimization Based Optimal DG Placement in Microgrids,” IEEE Transactions on Smart Grid, 5:5.

Weiss, C., 2016, “Addressing Aging Infrastructure Challenges with Advanced Materials, Characterization, and Modeling,” presented at the Advanced Materials for Transformative Changes to the Defense, Aerospace, and Civil Environments Workshop, Mississippi Research Consortium, Oxford, Mississippi (November). 

Argonne

Argonne National Laboratory

9700 South Cass Avenue

Argonne, IL 60439-4854

www.anl.gov 